\title{
THE WAYS OF EXPRESSING CONDOLENCES IMPLICITLY AND THEIR EFFECT ON SOCIOLINGUISTICS.
}

\author{
${ }^{1}$ Akobirova Sarvar Tuevna, ${ }^{2}$ Rasulmukhamedova Umida Alisherovna \\ ${ }^{1} \mathrm{PhD}$, Docent, Foreign languages department, Tashkent State University of Law, Tashkent, Uzbekistan. \\ E-mail: s.akobirova@tsul.uz \\ ${ }^{2}$ Teacher, Foreign languages department, Tashkent State University of Law, Tashkent, Uzbekistan. \\ E-mail: u.rasulmuhamedova@tsul.uz
}

\begin{abstract}
:
The article considers condolence as a form of English speech etiquette, analyzed as an expressive speech act. The relevance of teaching speech etiquette in a situation of condolence lies in the fact that the effectiveness of learning English increases in the conditions of modeling a real communicative situation. Linguistic means of speech act expression are considered. It introduces sociolinguistics by means of five areas of research: quantitative sociolinguistics, conversation analysis, register variation, discourse analysis, and the sociology of language.

Keywords: cross-cultural communication, condolence, speech etiquette, expressive speech act, discourse structure, sociology, implicitness
\end{abstract}

Article Received: 18 October 2020, Revised: 3 November 2020, Accepted: 24 December 2020

\section{Introduction}

The relations between the units of text expressed explicitly and implicitly are refracted through the prism of the consciousness of the sender and recipient of speech, they are aware of, as a result of which there is an understanding of the meaning of the text in full. Any situation is a complex unity consisting of a number of smaller propositions connected logically and structurally. In the process of encoding a mental situation by language means, the sender of the message solves the problem of the ratio of explicitly and implicitly expressed transmitted information. Accordingly, a number of propositions that describe this situation and appear to the author to be insignificant or easily restored from the content, do not find explicit expression in the finished text, and are reduced. Implicit propositions do not interfere with the creation of semantic unity, since it is easy to reconstruct the implicit if necessary. Implicit information is intertwined with explicit information and determines the meaning of the utterance [6]. Discourse in natural language is not always explicit. Many propositions may not be expressed, because the speaker believes that they are generally known or derived from explicit information. Thus, the finished text distinguishes sentences with reduced propositions based on presumption (the logical aspect of considering the phenomenon) and sentences with reduced propositions based on presupposition (the extralinguistic aspect). The language projections of such utterances are a simple sentence, a complex sentence of different types (compound and compound), and a complex syntactic whole [2].

In this article we will look at simple sentences with reduced propositions on the basis of the presumption. The existence of discrete and continuous levels in human consciousness allows the linguistic means available in language to convey the realities in the objective world in an implicit way. Using words and expressions in speech behavior, we take into account our own meaning and the implications derived from this meaning in a certain communication situation.

Materials and methods

Implicitness is a discrepancy between the content plan and the expression plan, an 
asymmetry. The asymmetry of relations between the units of the content plan and the units of the expression plan was most clearly justified By $\mathrm{S}$. Kartsevsky.

Implicit information can be transmitted according to two main strategies: maintaining implicitity and translating hidden information into explicit. In the first case, the transmission of implicatures is achieved by: 1) reproducing the language material of the original; 2) modifications of the language content of the source text. In the second case, to explicate implicit information, the translator resorts to: 1) specifying the values; 2) paraphrasing with the addition of vocabulary. The task of the translator is to create a text that is easy to read, while preserving the originality of the original. The problem of the features of the translation of implicit information, as well as implicit information as such, needs further development. First of all, it is necessary to develop a single conceptual apparatus, since many linguists in their work are repelled mainly from mathematical logic. So, a distinction is needed between the concepts of "implication". Some linguists consider them to be identical, while others, like V.Z. Demyankov and A.V. Kashichkin breed them on the process and the result [9]. It is important to continue to study the problem of subtext and its connection with implicit translation. Research in this area will help to improve the quality of translations of both fiction and scientific, technical and socio-political texts. A proper study of implicit information will increase the level of preservation of the individual identity of the translated texts.

The speech act is considered in the linguistic concepts of foreign and domestic authors, among which we should mention the names of researchers who have made a significant contribution to the development and interpretation of the theory of speech acts, classification of speech acts, postulates of speech behavior-Yu. d. Apresyan, N. D. Arutyunova, V. V. Bogdanov, V. Z. Demyankov, V. A. Zvegintsev, E. V. Paducheva, O. G. Pocheptsov, I. p. Susov, N. I.
Formanovskaya, Austin, T. A. dake, Farming L., S. Rybnoe, Y. Habermas, M. Halliday, Vanderveken, D. Wunderlich, J. Searle, J. Sadock, and others.

This definition is constantly being updated. The speech act is analyzed as the minimum basic unit of speech communication, in which one communicative goal of the speaker is realized and the addressee is affected [5]; RA is an elementary unit of speech, a sequence of language expressions uttered by one speaker [2]; RA is the final act in a series of other actions; the degree to which the speech act is universal is different [3]; RA is the choice of one of the many intertwined alternatives that form the "semantic potential" of the language [4].

In modern conditions, it is difficult to imagine that a language performs only one taskmessage transmission, i.e. its informative function. New communication conditions leave their mark on the participants of a conversation or letter. Now it is necessary to learn the language based on knowledge about the world and culture of the peoples of the language being studied and in inseparable unity with them. The effectiveness and efficiency of foreign language proficiency can be measured not only by excellent knowledge of grammar and understanding of certain information from the text, but also by mastering and mastering the rules of etiquette, as well as the conditions and culture of communication. Problems of crosscultural communication are given an increasing place in the scientific research of modern scientists [6]. S. G. Ter-Minasova identifies the following components of culture that have a national-specific color:

1) tradition(or stable elements of culture) and customs;

2) traditional-household culture;

3) everyday behavior (norms of communication);

4) " national pictures of the world "(perception of the surrounding world depending on national peculiarities of thinking);

5) art culture. 
The socio-cultural factor plays an irreplaceable role in the development of a foreign language. Any important social phenomenon is reflected in writing and speech. Each language serves the society where it is used as a native language. We have already mentioned that the components of society's culture consist of many components, so we can conclude that the importance of language in any culture is simply impossible to overestimate. The basic rules of speech etiquette in society always affect the norms of communication and behavior adopted in this culture. There are always rules that govern a particular communication situation. In some cases, they will be more stringent, in some less. In European culture, the attitude to death has always been unequivocally negative, and was perceived very mournfully. It is assumed that the deceased will leave with all honors and appropriate rituals will be performed by his relatives and relatives, who, in turn, can also count on the help and support of close people. Thus, the first thing to do in this situation is to offer condolences.

Condolence can be considered as a certain communicative act, which seems to belong to the category of expressive.

\section{Results and discussion}

Researchers have long noted that in the General space of communication there is a large proportion of such communication that cannot be carried out by means of language alone, including the share of non - verbal communication; in the General space of speech acts - the share of indirect speech acts. In the space of real communication, "discourses", in the organization of which such moments of standardization as design, plan, hyperteme are not assumed, significantly prevail over the actual texts and textoids [Sirotinina]. There is an infinite variety of meanings conveyed implicitly by speech units of various levels. It should be emphasized that the phenomena that, in our opinion, represent various varieties, particular ways of expressing the NC, include not only indirect statements, but also various indirect components of the content / implicature of language units. We can also talk about some General indirect tone of communication.

According to Searle also sets up 5 classes of illocutionary speech acts:[7]

- Representatives: Speech acts that commit a speaker to the truth of the expressed proposition; representations of a state of affairs, a true-or-false proposition (e.g., assessments, claims, statements, hypotheses, descriptions).

- Commissives: Speech acts that commit the speaker to a future action (e.g., promise, pledge, vow, threat).

- Directives: Speech acts that cause the addressee to think or do something (e.g., requests, commands, advice, requirements, invitations, challenges, dares).

- Declaratives: Speech acts that change reality in accord with the proposition of the declarative (e.g., bless, fire, arrest, christen, baptize, marry, appoint, apologize).

- Expressives: Speech acts that express a speaker's attitudes, emotions, or thoughts toward the proposition; not true or false.

Thus, at this point, there are three steps in speech act analysis, which are listed below and illustrated in Figure 1.

Three Steps in Speech Act Analysis:

1. Version in the grammatical form of the utterance

2. Version in the illocutionary class (or the function of the utterance)

3. Version in the situational context of use

Figure: Verson in Form-Function Mapping with Speech Acts

\begin{tabular}{|l|l|l|}
\hline Utterance/Form Class & Function & Context of Use \\
\hline I'm sorry. & Expressive & To apologize for a personal \\
\hline
\end{tabular}




\begin{tabular}{|l|l|l|}
\hline Declarative & & $\begin{array}{l}\text { violation; to } \\
\text { express condolences. }\end{array}$ \\
\hline I apologize. Declarative & Directive & $\begin{array}{l}\text { To attempt to get listener to } \\
\text { overlook something }\end{array}$ \\
\hline Excuse me. Imperative & Expressive & $\begin{array}{l}\text { To apologize for a social } \\
\text { violation. }\end{array}$ \\
\hline Pardon me. Imperative & Expressive & $\begin{array}{l}\text { To apologize for a social } \\
\text { violation. }\end{array}$ \\
\hline
\end{tabular}

I'm sorry and Excuse me can both be used as expressive but not in identical contexts. The first is for personal violations, and the second is for social violations. There are wide cross-cultural differences in perceptions of what a social and personal violation is. Also, I'm sorry is used to apologize and to express condolences. The same linguistic form has two communicative functions. This causes confusion in second language learning. Speech act theory can be applied in translation, cross-cultural communication, and language education as a way of understanding the conventions of a speech community and how miscommunication may occur.

Condolence is a certain social ritual, the essence of which is that the speaker, through speech acts of sympathy, comfort, conveys an understanding of deep grief, irreparable loss of the interlocutor, as well as a willingness to grieve with him. The ritual of condolence consists in uttering certain words in certain circumstances and in relation to a certain addres, that is, the addressee needs to know where, when, to whom and what to say, so that what is said is perceived as a willingness to share misfortune with him. However, although dictionaries do not note that this interpretation is currently outdated, modern native speakers perceive it as having lost its meaning and even strange.

Condolence is a performative act, since the illocutionary power of an utterance is revealed in it using an illocutionary verb in the corresponding form(present tense, first person, singular, indicative mood, active voice) - the form of a performative (2). such performative verbs are to condole, to be sorry. "V+N" designs are also widely represented»:

«I'm very sorry to hear about the loss of your grandfather».

«I just heard about your dad. I am so sorry and wanted to offer my condolences».

«I am so sorry and I want you to know I am thinking of you and what you and your family must be going through right now».

«I'm sorry I never had a chance to meet your mother, although we spoke on the phone several times»

«There is no good time or way for someone you care about to die and I am sorry to find out that your dad's brother is making this even more painful for you and for your brothers»

«I am truly sorry to hear of your recent loss of your dad»

«I was so sorry to hear of George's death»

«I don't know what to say Pete, except that I'm so, so sorry to hear about the death of your mom»

«I am sorry to find out that your dad's brother is making this even more painful for you and for your brothers» [10].

An important feature of the forms of expressing condolences is that the speech act and its implementation in speech coincide, hence the use of present tense forms: 
«I want you to know that my thoughts are with you during this difficult time»

«Terry and I grieve with you in the loss of your son»

«I know mere words may offer but little comfort at this tragic time, but know that my deepest feelings of sympathy lie with you and your family»

«I am very sorry that he is no longer with you»

«I don't know what to say Pete, except that I'm so, so sorry to hear about the death of your mom» $[10]$

Thus, a condolence is a speech act or a communication act that embodies the unity of locution, illocution, and perlocution ( the resulting state: experience of grief, loss, misfortune, etc. ) the discourse of condolence can contain both implicit and explicit forms of expression. An implicit offer of help can be attributed, because according to the tradition of" so accepted " rules of etiquette, to offer help, thereby condoling. To explicit, directly, the very expression of condolences.

Thus, the analysis has shown that speech etiquette is an important component of interpersonal communication, compliance with the rules and norms of which is a requirement of modern inter-cultural communication, the relevance of studying which, in turn, is of unprecedented importance in a modern multicultural society. Knowledge about the etiquette of behavior has always been highly valued by a person, especially in such non-routine cases as death. Thoughts about the death of a close relative or friend are always avoided, this is natural and often takes you by surprise. The sympathizer is expected to be ready to share the grief, support the mourner with personal presence or memory of the deceased, and give their time. Material, physical or organizational assistance is welcome.

\section{Conclusion}

Sociative expressive speech acts implement socially defined regulatory rules of speech behavior with mandatory positive evaluation: the concept of benevolence is explicitly or implicitly included in the meaning of any sociative utterance, as evidenced by their internal form. The social-ritual type of discourse is closely related to the conventional nature of communicative acts. The Convention refers to the forms of interaction accepted in a given society (regulated by this society), including speech. Most communication acts are regulated to some extent, and it is probably more convenient for speakers when there are regulations than when there are no regulations. Conventions that regulate etiquette acts of communication are the conditions necessary for successful interaction within regulated speech situations. "A huge number of speech acts are stereotyped and repeat what has already been repeated millions of times by members of the same language group with only minor modifications. This means that many situations evoke identical reactions in us, and that the language forms of these reactions - whole sentences-are well-developed. Their utterance is almost automatic. They are stored in memory, probably, the same way as a single word, phraseological units, complete and not collected units. In everyday speech, not only wellestablished units of the nomination, not only stamps of individual segments of the utterance, but also entire utterances are reproduced in the form of ready-made samples.

In many European countries, it is customary to respond to the death of a person in writing since the XVIII century. A letter is an acceptable means of expressing condolences, since it is not always possible to convey your words verbally. The reason for writing such a letter is unpleasant, so its content is transmitted in essence, without empty words and tactlessness. A large number of words describing good deeds and deeds during the life of the deceased are present in the letter written in his honor.

Condolence refers to expressive speech acts, because the speaker expresses his feelings 
and attitude to what is happening, expressing an emotional impact on the recipient.

\section{References}

[1] Holmes, Janet. 1992/2001/2008. An Introduction to Sociolinguistics. Third edition. London: Pearson Longman.

[2] Hymes, Dell. 1974. Foundations in Sociolinguistics. Philadelphia: U. of Pennsylvania Press.

[3] Hymes, Dell. 1972. On communication competence. In Sociolinguistics. J.B. Pride and Janet Holmes (eds). Baltimore: Penguin Books.

[4] Janda, Richard. 1985. Note-taking as a simplified register. Discourse Processes 8.437-54. Labov, William. 1982. Objectivity and commitment in linguistic science: The case of the Black English trial in Ann Arbor. Language in Society 11.165-201.

[5] Vezhbitskaya A. Speech acts// New in foreign linguistics, Moscow, 1985. Issue 16: Linguistic pragmatics, Pp. 251-276.

[6] Ter-Minasova S. G. Language and intercultural communication, Moscow: Slovo, 2000.

[7] SERL J. R. What is a speech act? // New in foreign linguistics. Issue 17: Theory of speech acts; General ed. by B. Y. Gorodetsky. M.: Progress, 1986. Pp. 151169.

[8] Sayings for Sample Letters of Sympathy and Condenses. Access mode: http://obituarieshelp.org/sample_letter_sympathy_condolence_hub.html (date of request: 4.11.2014.)

[9] Biber, Douglas, Susan Conrad, and Randy Reppen. 1998. Corpus Linguistics: Investigating Language Structure and Use. Cambridge: Cambridge UP.

[10] Baklanova, I. I. the Image of the author of a journalistic work in the mirror of the implicit content of the text / I. I. Baklanova, M. Yu. Fedosyuk / / Bulletin of the Russian rhetorical Association. - 2005. - Issue 7 (15).-P. 10-22. 